\title{
Shifts in Microbial Community Composition and Physiological Profiles across a Gradient of Induced Soil Degradation
}

Guilherme M. Chaer*
Embrapa Agrobiologia
BR-465, km 7
Caixa Postal 74505
Seropédica, RJ, Brazil 23890-000
Marcelo F. Fernandes
Embrapa Tabuleiros Costeiros
Av. Beira Mar, 3250
Sementeira
Aracaju, SE- Brazil 49025-040
David D. Myrold
Peter J. Bottomley
Dep. of Crop and Soil Science
Oregon State Univ.
3017 Ag \& Life Sciences Bldg.
Corvallis, OR 97331-7306

\begin{abstract}
A disturbance gradient was created to evaluate the relationship between changes in soil physical and chemical properties with microbial community composition. Plots of a 12-yr fallow Ultisol in Northeastern Brazil were arranged in a Latin Square design and disturbed by tillage events applied zero, one, two, three, or four times over a 3-mo period. Sixty days after the last event, plots were sampled $(0-20 \mathrm{~cm})$ and soil analyses performed. Tillage resulted in a linear disturbance gradient characterized by significant declines in soil available water, saturated hydraulic conductivity, soil aggregation, organic $\mathrm{C}$, and microbial biomass. The disturbance gradient also affected soil microbial communities, but the changes observed were dependent on the profiling technique used. The application of one tillage event significantly altered terminal restriction fragment length polymorphism (T-RFLP) profiles, which remained unchanged on further disturbances. In contrast, community level physiological profiles (CLPPs) continued to change as disturbance levels increased and were significantly correlated with most soil properties associated with soil degradation. Phospholipid fatty acid (PLFA)-based assessment of microbial community structure was the least sensitive to disturbance, showing significant changes only between the control plots and those subjected to four tillage events. Nevertheless, the linear shift observed in a PLFA biomarker of bacterial stress (ratio of 19:0cy to 18:1w7c) in response to the disturbance gradient was consistent with physiological changes in the CLPPs. The results clearly illustrate that microbial community responses to increasing levels of soil physical disturbance can be detected at physiological (CLPPs), biochemical (PLFA), and genotypic (T-RFLP) levels; however, they are not synchronously coupled. Further studies are needed to determine if there is functional significance to the physiological responses to disturbance that are, or are not, accompanied by community composition changes.
\end{abstract}

Abbreviations: CEC, cation exchange capacity; CLPP, community level physiological profile; FAME, fatty acid methyl ester; $H$, Shannon index; NMS, non-metric multidimensional scaling; PLFA, phospholipid fatty acid; R, richness index; SOC, soil organic carbon; SOM, soil organic matter; T-RFLP, terminal restriction fragment length polymorphism; T-RFs, terminal restriction fragments; WSA; water stable aggregates.
$\mathrm{T}$ he effects of land use change and agriculture practices on the composition and diversity of soil microbial communities have been demonstrated using both genetic and physiological techniques. Buckley and Schmidt (2001) showed that fields sharing a history of cultivation possessed different T-RFLP profiles, and reduced diversity of rRNA genes associated with $\alpha$-Proteobacteria, $\beta$-Proteobacteria, and Actinobacteria compared with uncultivated fields. Microbial community structure also differed between cultivated and uncultivated soils based on PLFA analysis (Bossio et al., 2005). Soils that were tilled

Soil Sci. Soc. Am. J. 73:1327-1334

doi:10.2136/sssaj2008.0276

Received 20 Aug. 2008.

*Corresponding author (gchaer@cnpab.embrapa.br).

(c) Soil Science Society of America

677 S. Segoe Rd. Madison WI 53711 USA

All rights reserved. No part of this periodical may be reproduced or transmitted in any form or by any means, electronic or mechanical, including photocopying, recording, or any information storage and retrieval system, without permission in writing from the publisher. Permission for printing and for reprinting the material contained herein has been obtained by the publisher.
(Lupwayi et al., 1998) or converted from native vegetation to agriculture (Gomez et al., 2000, 2004; Nsabimana et al., 2004) presented different CLPP, and reduced physiological diversity. Despite these well established facts, it remains unclear what delineates a situation where a soil community makes physiological adjustments to environmental disturbance without undergoing community composition change, from one where there is a concomitant community shift (Schimel et al., 2007). Furthermore, it is unknown to what extent a shift in community composition results in greater community resistance to further abuse and buffers against further shifts in composition. In most situations the ability to make this type of association would have been impaired because the responses of microbial communities to treatments might have been influenced by non-edaphic factors. For example, Yan et al. (2000) associated the reduced physiological diversity of cultivated vertisols assessed by the CLPP method with reduced soil organic C compared with uncultivated vertisols. However, this difference could also be the result of other factors influencing soil microbial diversity, such as the history of chemical applications to cultivated fields in the form of fertilizer, insecticides, and herbicides, and higher plant diversity in the uncultivated sites. In another study, the evaluation of a grassland restoration 
chronosequence following ski run construction indicated that the high catabolic diversity of older restored soils was associated with improvements in soil physicochemical properties (Gros et al., 2004). Nevertheless, the fact that the older restored soils also possessed higher plant diversity and biomass relative to the younger sites cannot be ignored as a confounding factor because the composition of plant species and the quantity of carbon inputs have also been shown to influence soil microbial diversity and composition (Berg et al., 2002; Grayston et al., 2004; Hackl et al., 2004; Kowalchuk et al., 2002; Smalla et al., 2001).

In this study, we designed an experiment to induce a gradient of soil degradation by applying a varying number of tillage events to a previously undisturbed site. This gradient allowed us to follow both the degradation of soil physical and chemical properties induced by the disturbance treatments and the concomitant changes in microbial activity and composition. The control of non-edaphic confounding variables provided by the experimental conditions allowed these associations to be established without the biases usually associated with observational studies. Soil microbial community changes were evaluated using a multiple set of complementary techniques that included PLFA and T-RFLP profiling to evaluate changes in structural composition, and an analysis of CLPPs in Biolog EcoPlates (Biolog, Inc., Hayward, CA) to evaluate physiological changes. We compared the relative sensitivities of these techniques to indicate soil degradation, and evaluated how changes in microbial community composition are associated with physiological changes.

\section{MATERIALS AND METHODS \\ Site Descriptions and Experimental Design}

The study site is located at the Umbaúba Experimental Station, Embrapa Coastal Tablelands, Sergipe State, Northeastern Brazil (11 $11^{\circ} 16^{\prime} \mathrm{S}$, $37^{\circ} 26^{\prime} \mathrm{W}, 105 \mathrm{~m}$ altitude; $1350 \mathrm{~mm}$ of annual rainfall; $24.3^{\circ} \mathrm{C}$ mean daily temperature). The soil is a fine-loamy kaolinitic isohyperthermic Typic Fragiudults (Latossolo Amarelo, according to Brazilian Soil Taxonomy). This area was deforested $30 \mathrm{yr}$ ago, cultivated with maize (Zea mays L.), cassava (Manihot esculenta), and cowpea (Vigna unguiculata) for the next $16 \mathrm{yr}$ and then kept fallow for $12 \mathrm{yr}$ before this experiment. During the fallow period the area was mown every other year.

Experimental plots $(36 \times 12 \mathrm{~m})$ were laid out in a Latin Square design with five treatments (disturbance levels) that consisted of the application of one, two, three, or four tillage events, plus a no-till control (Table 1). Each tillage event consisted of two plowing operations (disk plow), each followed by two disking operations. These treatments were designed to establish a gradient of induced soil degradation in a

Table 1. Sequence of tillage events designed to induce the gradient of soil degradation. The check mark symbol indicates the dates when the tillage events were performed. Each tillage event consisted of two plowing operations, each of which was followed by two disking operations. Soils were sampled in November 2006, $60 \mathrm{~d}$ after the last tillage event.

\begin{tabular}{ccccc} 
Disturbance level & \multicolumn{4}{c}{ Tillage date } \\
\cline { 2 - 5 } (tillage events) & Jun 27 & Jul 19 & Aug 7 & Sep 15 \\
\hline 0 (control) & & & & \\
1 & & & & $\checkmark$ \\
2 & & & $\checkmark$ & $\checkmark$ \\
3 & & $\checkmark$ & $\checkmark$ & $\checkmark$ \\
4 & $\checkmark$ & $\checkmark$ & $\checkmark$ & $\checkmark$ \\
\hline
\end{tabular}

short period ( $3 \mathrm{mo})$, based on the assumption that the extent of degradation of soil structure and decomposition of soil organic matter (SOM) would increase with the number of tillage events. Treatments were applied from July through September of 2006 with a 2- to 5-wk interval between tillage events. The minimum interval between consecutive events was determined as the time necessary for the $\mathrm{CO}_{2}$ flux in disturbed plots to decline to a rate that was equal to, or less than, the rate observed in control plots (flux of soil $\mathrm{CO}_{2}$ was measured twice a week using soda lime traps (Zibilske, 1994) installed in both the most recently tilled and control plots). After this period, tillage operations commenced as soon as soil moisture conditions were optimal. Fifteen days before the first tillage event, the vegetation of the experimental area (grasses and small shrubs) was killed with a glyphosate application. Vegetation that grew on the plots during the course of the experiment was mechanically mown monthly until November 2006.

\section{Soil Analyses}

Soil samples were collected in November 2006, $60 \mathrm{~d}$ after the last tillage event had been applied to all experimental plots (Table 1). Ten random soil cores were collected from 0 - to 20-cm depth of each plot and pooled to form one composite sample per plot. Samples were passed through a 4-mm mesh sieve, and air dried. Subsamples were refrigerated at $4^{\circ} \mathrm{C}$ for PLFA and CLPP, and frozen at $-20^{\circ} \mathrm{C}$ for T-RFLP analysis. Cation exchange capacity (CEC) was calculated as the sum of $\mathrm{H}^{+}+\mathrm{Al}^{3+}$ (extracted by $0.5 \mathrm{M}$ calcium acetate buffer, $\mathrm{pH}$ 7.0) and bases cations $\left(\mathrm{Ca}^{2+}, \mathrm{Mg}^{2+}, \mathrm{K}^{+}, \mathrm{Na}^{+}\right)$(Embrapa, 1997). Soil organic matter content was measured as the loss of weight on ignition after heating oven-dry soil samples at $430^{\circ} \mathrm{C}$ for $24 \mathrm{~h}$. A conversion factor of 1.724 was used to convert organic matter to soil organic carbon (SOC) (Nelson and Sommers, 1996). The stability of soil aggregates in water was determined by a standard wet sieving method using a reciprocating shaking apparatus. Air-dried aggregates $(1-2 \mathrm{~mm})$ were slowly rewet by capillarity and placed on the top of a $0.25-\mathrm{mm}$ mesh sieve. The sieving was accomplished with a 4 -cm stroke length at 42 cycles $\mathrm{min}^{-1}$ for $5 \mathrm{~min}$. The mass of sand $>0.25 \mathrm{~mm}$ was determined after dispersion of the fraction retained on the sieve in $\mathrm{NaOH}\left(2 \mathrm{~g} \mathrm{~L}^{-1}\right)$ (Kemper and Roseneau, 1986). Water stable aggregates (WSA) were expressed as the ratio between the masses of the soil fraction retained in the sieve (free of $>0.25-\mathrm{mm}$ sand) and the whole soil sample. Soil samples $(<4 \mathrm{~mm})$ were used to determine the weighted mean diameter of soil aggregates (Kemper and Roseneau, 1986) after sorting the aggregates by wet sieving and using nested sieves with openings of 2, 1, 0.5, and $0.25 \mathrm{~mm}$ (Nimmo and Perkins, 2002). The Yoder apparatus setting was the same as used for WSA. Available soil water and bulk density were determined in two undisturbed soil core samples collected from the 7.5 - to $12.5-\mathrm{cm}$ depth of each plot. Available soil water, defined as water held between -10 and $-1500 \mathrm{kPa}$, was measured using the pressure plate extractor method (Dane and Hopmans, 2002). Bulk density was determined by the core method (Grossman and Reinsch, 2002). Field-saturated soil hydraulic conductivity was determined using a double ring infiltrometer (Reynolds et al., 2002). Readings were taken at $10 \mathrm{~min}$ interval between 20 and $70 \mathrm{~min}$ after water addition to the rings. After the initial $20 \mathrm{~min}$, all the plots had reached quasi-steady flow (equilibration time). The measurements were performed in duplicate in each plot.

\section{Community Level Physiological Profiles}

Community level physiological profiles were obtained with Biolog EcoPlates as described by Sinsabaugh et al. (1999). Each plate was inoculated with $150 \mu \mathrm{L}$ per well of soil sample suspension (1:100 dilu- 
tion) and incubated at $25^{\circ} \mathrm{C}$. Each plate contained triplicate wells of 31 substrates. The negative control corresponded to a well without any $\mathrm{C}$ source. Optical density at $596 \mathrm{~nm}$ was read at 24, 48, 72, and $96 \mathrm{~h}$ using a microplate reader BioTek PowerWave X 340 (BioTek Instruments, Inc., Winooski, VT). Absorbance values for each of the 31 substrates were corrected by subtraction of the blank control value (raw difference; RD). Negative RD values were set to zero. To minimize the effects of different inoculum densities, data were normalized by dividing the RD values by their respective average well color development (AWCD) values (Garland and Mills, 1991).

\section{Phospholipid Fatty Acid Profiles}

Extraction procedures and reagents for the PLFA analysis were similar to those described by Butler et al. (2003). The PLFA composition of extracts was analyzed using an Agilent 6890 gas chromatograph (Agilent Inc., Palo Alto, CA) equipped with an HP Ultra-2 (5\% phenylmethylpolysiloxane) column and flame ionization detector. The identification of fatty acid methyl esters (FAMEs) was based on a comparison with chromatograms produced from a mixture of 37 FAMEs (FAME 37 47885-4; Supelco Inc., Bellefonte, PA), a mixture of 24 bacterial FAMEs (P-BAME 24 47080-U; Supelco), 10Me16:0, and 10Me18:0 (Matreya, Pleasant Gap, Pa.), and 20:4w6c (Supelco). A standard curve prepared from a solution of tridecanoic acid methyl ester (Supelco) was used to convert chromatographic areas into nanomoles of FAMEs.

The FAMEs analyzed included those that formed peaks in the region between tetradecanoic methyl ester (14:0) and arachidonic acid $(20: 4 \omega 6 \mathrm{c})$. Uncommon FAMEs, defined as those with masses $<4 \%$ of the mass of FAME 16:0, were excluded from the data matrix. Profile composition was expressed in mol\% of PLFAs, after standardizing the mass of individual PLFAs by their totals within each sample.

Fatty acid methyl esters reported to be biomarkers of fungi, Gramnegative bacteria, Gram-positive bacteria, actinomycetes, and arbuscular mycorrhizal fungi were used as signatures for these microbial groups (Frostegård and Bååth, 1996; Olsson et al., 1995; White et al., 1997; Zelles, 1999). The biomass of the FAME 16:0 ( $\mathrm{nmol} \mathrm{g}^{-1}$ soil) was used as an estimator of microbial biomass (Zelles et al., 1992), and the ratio of cyclopropyl (19:0cy) and its precursor fatty acid $(18: 1 \omega 7 \mathrm{c})$ was used as a stress indicator (Law et al., 1963).

\section{DNA Extractions and Amplification}

From each plot, 1-g samples of frozen soil $\left(-20^{\circ} \mathrm{C}\right)$ were extracted using a MoBio PowerSoil DNA isolation kit (MoBio Laboratories, Carlsbad, CA), according to manufacturer's instructions except that a Bio101 FastPrep instrument was used to lyse cells (Bio 101, Carlsbad, CA). The MoBio bead beating tubes were shaken for 45 s on the FastPrep, and the DNA in extracts was quantified using a NanoDrop ND-1000 UV-visible spectrophotometer (NanoDrop Technologies, Wilmington, $\mathrm{DE})$, and subsequently diluted to $25 \mathrm{ng} \mu \mathrm{L}^{-1}$.

The primers used for amplification of the bacterial 16S rRNA gene were: 8F (Edwards et al., 1989), and 907R (Muyzer et al., 1995). The thermal cycling parameters were as previously described (Hackl et al., 2004). The quality of polymerase chain reactions (PCR) products was determined by electrophoresis of $5 \mu \mathrm{L}$ PCR product in $1 \%(\mathrm{w} / \mathrm{v})$ agarose gels containing ethidium bromide $\left(0.5 \mathrm{mg} \mathrm{mL}^{-1}\right)$. The PCR products were purified using Qiagen DNA clean-up kit (Qiagen, Valencia, CA) to eliminate genomic DNA, excess primers, and unused nucleotides.

\section{Terminal Restriction Fragment Length Polymorphism Profiles}

The PCR products were digested using three restriction enzymes: CfoI, RsaI, and MspI (Promega Corp., Madison, WI). Restriction digests were incubated according to manufacturer's specifications for $3 \mathrm{~h}$ at $37^{\circ} \mathrm{C}$, followed by heat inactivation at $65^{\circ} \mathrm{C}$ for $15 \mathrm{~min}$. Restricted samples (approximately $1 \mathrm{ng}$ of amplified DNA equivalent) were submitted to the Oregon State University Center for Genome Research and Biocomputing for analysis using a ABI Prism 3100 Genetic Analyzer (Applied Biosystems, Foster City, CA) and the GeneScan V3.5 software (Applied Biosystems). The baseline threshold for signal detection was set to 50 fluorescence intensity units. Electropherograms were transformed into numeric data of individual peak heights using the Genotyper V2.5 software (Applied Biosystems). To minimize the effects of different quantities of PCR products, data were normalized by dividing the fluorescence value of each T-RF by the total fluorescence of all T-RFs from the corresponding sample. After examining the electropherograms of negative controls, peaks contributing $<1.5 \%$ of the total fluorescence in a single profile were excluded, and the relative fluorescence recalculated, making the sum of each profile equal to $100 \%$ (Rich et al., 2003). Peaks were aligned by base pairs and any peaks less than two base pairs apart were combined for final fragment identifications. The three enzyme digest profiles of a specific sample were combined to produce composite T-RFLP profiles.

\section{Statistical Analyses}

A regression approach applied to the $5 \times 5 \times 5$ Latin Square was used to evaluate treatment effects on univariate data (S-PLUS ${ }^{\circ}$ 8.0, Insightful Corp.). When the relationship between soil variables and disturbance level was not linear, a two-sided multiple comparison with a control (MCC) test was used to evaluate treatment effects. Raw values of soil properties obtained for each experimental plot were subtracted from the respective row and column coefficients before graphic presentations. A similar correction was applied to the individual FAMEs, C sources, or T-RFs before the multivariate analyses. Each community data set was ordinated using non-metric multidimensional scaling (NMS) (Kruskal, 1964a, 1964b) and Euclidean distance. Ordinations were performed using PC-ORD statistical package, V5 $\beta$ (B. McCune and M.J. Mefford, PC-ORD for Windows: multivariate analysis of ecological data, MjM Software, Gleneden Beach, OR). Resulting bidimensional ordinations were rotated to maximize the explained variance on Axis 1. The resulting scores from Axis 1 were then plotted against the disturbance levels (number of tillage events) to evaluate treatment effects on microbial community composition and CLPPs. The relationships between changes in microbial community and soil physical, chemical, and biological properties were evaluated by applying the Pearson productmoment correlation coefficient between the Axis 1 scores and each soil property. The PLFA-microbial groups, and CLPP-substrate categories (polymers, carbohydrates, carboxylic acids, amino acids, and amines/ amides) were also correlated with their respective Axis 1 scores.

Non-metric multidimensional scaling ordination was also performed using soil variables that included physical and chemical properties and the PLFA-based microbial biomass. Rotation of ordination axes and representation of Axis 1 along the disturbance levels were performed as described for microbial community data. This procedure was used to determine the formation of the induced disturbance gradient and to associate it with changes in microbial profiles. Therefore, Axis 1 scores from the soil variables were correlated with Axis 1 scores obtained from the CLPP, T-RFLP, and PLFA ordinations. 
To allow for comparison with previous studies, richness, and diversity indexes were calculated based on the microbial community data sets using PC-ORD. Richness $(R)$ was defined as the total number of FAMEs or T-RFs detected, or substrates utilized in Biolog plates for a given sample. The Shannon index $\left(H^{\prime}\right)$ was calculated according to the following equation: $H^{\prime}=-\sum p_{i} \log p_{i}$, where $p_{i}$ is the proportion represented by each FAME, T-RF, or catabolic activity relative to their totals. These indexes were analyzed statistically as described for soil properties.

\section{RESULTS}

\section{Effect of Disturbance Treatments on Soil Properties}

The increasing levels of soil disturbance simulated by multiple tillage events caused significant changes in most of the soil physical and chemical properties analyzed (Fig. 1A-G). Soil available water, defined as the volume of water held by the soil between field capacity $(-10 \mathrm{kPa})$ and wilting point $(-1500 \mathrm{kPa})$, decreased linearly $(p<0.001)$ from $0.27 \mathrm{~m}^{3} \mathrm{~m}^{-3}$ in control plots to $0.19 \mathrm{~m}^{3} \mathrm{~m}^{-3}$ in the most disturbed plots (Fig. 1A). These changes resulted both from linear decreases in soil water reten- tion capacity, and increases in wilting point across the disturbance gradient (data not shown). Field measurements of saturated hydraulic conductivity were reduced from $4.3 \mathrm{~cm} \mathrm{~h}^{-1}$ in control plots to nearly zero in treated plots (Fig. 1B). Disturbance also affected the percentage of WSAs which decreased from $90 \%$ in control plots to 79 to $83 \%$ in plots submitted to more than two tillage events (Fig. 1C). A similar pattern was observed for the aggregate mean diameter (Fig. 1D). Although soil bulk density tended to increase at the highest disturbance level, differences relative to the control were not statistically significant (Fig. 1E). There was a small, but significant $(p<0.05)$ decrease in soil organic $\mathrm{C}$ (SOC) from $24 \mathrm{~g} \mathrm{~kg}^{-1}$ in controls to about $22 \mathrm{~g} \mathrm{~kg}^{-1}$ in treated plots irrespective of disturbance level (Fig. 1F). A similar trend was observed in the CEC measured at $\mathrm{pH} 7$, which decreased from 5.2 to $4.7 \mathrm{cmol}_{\mathrm{c}} \mathrm{kg}^{-1}$ in the same set of treatments $(p<$ 0.10) (Fig. 1G). Disturbance treatments affected the PLFAbased microbial biomass estimate (Fig. $1 \mathrm{H}$ ). Accordingly, the amount of 16:0 decreased from $2.2 \mathrm{nmol} \mathrm{g}^{-1}$ in undisturbed plots to $1.6 \mathrm{nmol} \mathrm{g}^{-1}$ in plots submitted to four tillage events.
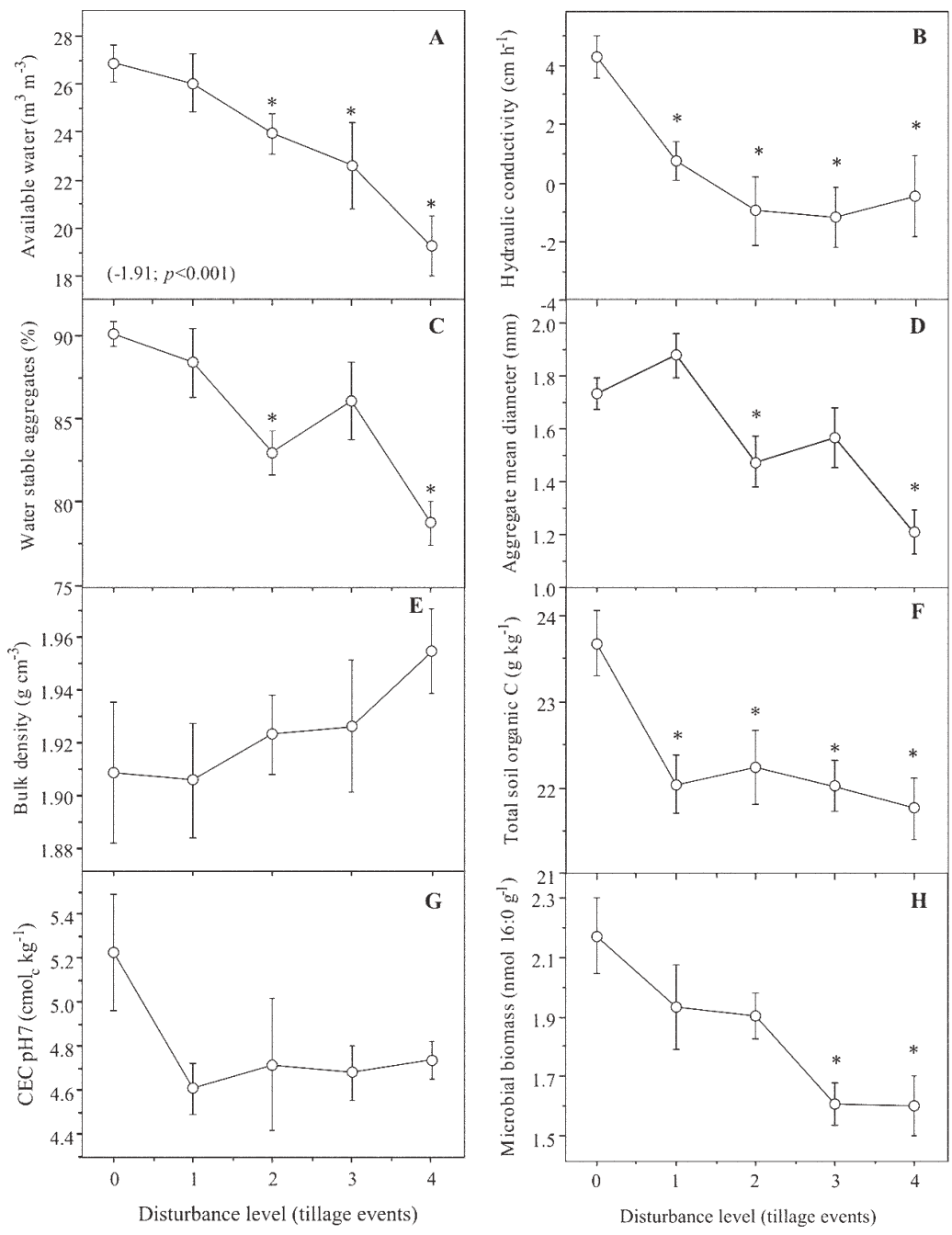

Fig. 1. Changes in soil properties in response to the disturbance level applied to the soil as tillage events. Variables were adjusted to account for row and column effects associated with the Latin Square design (see Statistical analysis for details), which is why values can be $<0$ for some properties. Vertical bars correspond to the mean standard error $(N=5)$. Asterisks indicate significant difference from controls $(p<0.05)$. Values in parentheses indicate the slope and $p$-value of the linear regression.

\section{Disturbance Effects on Soil Microbial Community}

Non-metric multidimensional scaling ordination represented $94 \%$ of the total data variance of both the CLPP and T-RFLP profiles in two dimensional solutions. For the PLFA data, the total variance explained in two axes reached $98 \%$. To simplify the visualization of treatment effects on the microbial community and physiological profiles, ordination axes were rotated to maximize the variance on Axis 1 which was plotted against the disturbance levels (Fig. 2). After rotation, Axis 1 represented between 81 and $89 \%$ of the total variance in the three data sets. Results showed increasing changes in the CLPPs with increasing disturbance level (Fig. 2A). These changes were driven by shifts in the pattern of utilization of specific categories of $\mathrm{C}$ substrates. The greater the disturbance applied, the higher was the relative use of polymers and carboxylic acids as indicated by their positive correlation coefficients along Axis $1(r=$ 0.86 and 0.91 , respectively, Table 2). Conversely, there was a decrease in the relative use of amines/ amides and carbohydrates with increasing disturbance ( $r=-0.86$ and -0.68 , respectively).

The T-RFLP profiles were also significantly altered in tilled plots, but changes were not proportional to the disturbance levels as observed in the CLPPs (Fig. 2B). A single tillage event resulted in a new genetic profile of the microbial community that was unaltered by further disturbances to the soil.

The PLFA profiles were less sensitive to disturbance treatments compared with T-RFLP and CLPP (Fig. 2C). Significant differences relative to controls were only observed in plots submitted to the highest disturbance level (four tillage events). Correlation coefficients between PLFA markers from major microbial groups and 
Table 4. Correlation coefficients $(r)$ between richness $(R)$ and Shannon index $\left(H^{\prime}\right)$, and scores from the NMS ordination (Axis 1) representing changes in the community level physiological profile (CLPP), T-RFLP, and PLFA profiles (Fig. 3). Negative correlation coefficients indicate that changes in microbial profiles in response to soil disturbance were associated with a decrease of the diversity indexes.

\begin{tabular}{llll} 
& CLPP & T-RFLP & PLFA \\
\hline Richness $(R)$ & $-0.74^{* * *}$ & $-0.49^{* *}$ & 0.07 \\
Shannon index $\left(H^{\prime}\right)$ & $-0.91^{* * *}$ & $-0.67^{* * *}$ & 0.07 \\
\hline
\end{tabular}

$* * p<0.01$.

$* * * p<0.001$.

Nevertheless, correlations between all three microbial profiles and individual soil properties indicated a significant association with soil organic $\mathrm{C}$ and hydraulic conductivity (Table 5). The negative sign of the correlation coefficient indicated that changes in CLPP, T-RFLP, and PLFA profiles in response to soil disturbance were associated with lower values of soil $\mathrm{C}$ and hydraulic conductivity $(p<0.05)$. Although none of the other soil properties were correlated with the T-RFLP and PLFA profiles, correlations between CLPPs and microbial biomass, CEC, available water, aggregate mean diameter, and WSAs were highly significant $(p<0.001)$.

\section{DISCUSSION}

\section{Effects of the Induced Gradient of Degradation}

Multiple tillage treatments were effective in forming a disturbance gradient during the 5-mo period of the field experiment. Degradation was expressed as sequential decreases of soil available water, water infiltration, aggregate mean diameter, and WSA (Fig. 1A-D). In addition to physical changes, SOC decreased in disturbed plots, irrespective of the number of tillage events (Fig. $1 F, G)$. Loss of SOM from tilled soils has been widely reported in the literature, but it is generally referred to as a long-term effect of tillage (Doran et al., 1998; Elliott, 1986; Woods, 1989). In our study, it is likely that a large portion of the $\mathrm{C}$ lost in response to the first tillage was derived from the decomposition of an ex-

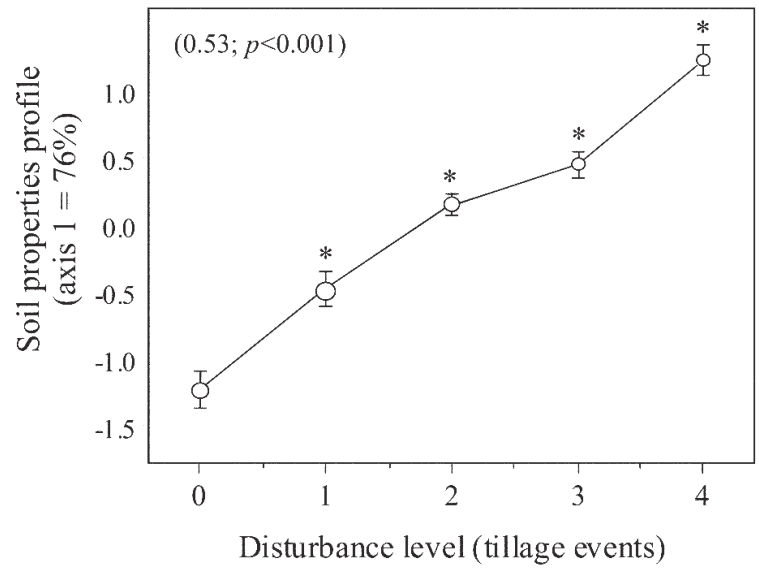

Fig. 4. Soil properties profile in relation to the disturbance level applied to the soil. It represents the axis $\mathbf{1}$ scores of the Non-metric multidimensional scaling (NMS) ordination of soil properties shown in Fig. 1. The fraction of the total variance accounted for in Axis 1 is indicated in parentheses. Vertical bars correspond to the mean standard error $(N=5)$. Asterisks indicate significant difference from control $(p<0.05)$. Values in parentheses indicate the slope and $p$-value of the linear regression. tremely labile pool of organic matter. This suggestion is corroborated by an increase of up to $100 \%$ in $\mathrm{CO}_{2}$ flux from recently tilled plots compared with controls (data not shown). This difference in $\mathrm{CO}_{2}$ flux remained relatively constant for about $10 \mathrm{~d}$, indicating that it was caused by an increase in microbial respiration activity rather than by a short-lived physical process of soil degasification that has been observed in other soils (Jackson et al., 2003). Because tilled plots had lower microbial biomass (Fig. 1H), higher respiratory activity was also probably due to the decomposition of microbial cells killed by the disturbance. Furthermore, the more stable pools of SOM should also be considered as a source of C, especially in tropical, coarse-textured soils like the one evaluated in this study. Decreases in stable SOM pools could be a major reason for the decrease in soil CEC (Fig. 1G) because they are responsible for most of the CEC contributed to the soil by organic matter (Brady and Weil, 2002).

\section{Response of Soil Microbial Communities to the Induced Disturbance Gradient}

Although the disturbance gradient significantly affected soil microbial communities, the changes observed were dependent on the profiling technique used. The changes observed in CLPPs were proportional to the disturbance level; however, this pattern was not followed by the community structure (PLFA and T-RFLP) (Fig. 2A-C). For example, the T-RFLP profiles changed similarly in all tilled plots independent of the disturbance level. These results indicate that in spite of the similar microbial composition in disturbed plots, these communities differed in regard to their physiological status. According to CLPPs, physiological changes were associated with a relative decrease in the catabolism of amines/amides and carbohydrates, accompanied by an increase in the catabolism of polymers and carboxylic acids across the disturbance gradient (Table 2). It is intriguing to consider the possibility that the changes in CLPPs to each tillage event reflect exhaustion of the labile pool of SOM during the first disturbance, and the community subsequently switching to use (i) more oxidized pools of SOM exposed by destruction of large WSA during Tillage Event 2, and (ii) C made

Table 5. Correlation coefficients $(r)$ between soil properties profile, or individual soil properties, and scores representing changes in the community level physiological profile (CLPP), terminal restriction fragment length polymorphism (T-RFLP), and phospholipid fatty acid (PLFA) profiles (Fig. 3). Negative correlation coefficients indicate that changes in microbial profiles in response to soil disturbance were associated with a decrease in the respective soil property.

\begin{tabular}{llll} 
& \multicolumn{1}{c}{ CLPP } & \multicolumn{1}{c}{ T-RFLP } & \multicolumn{1}{c}{ PLFA } \\
\hline Soil properties profile & $0.64^{* * *}$ & 0.13 & 0.14 \\
Microbial biomass & $-0.59^{* * *}$ & -0.07 & -0.13 \\
Soil organic C & $-0.62^{* * *}$ & $-0.65^{* * *}$ & $-0.42^{*}$ \\
CEC & -0.15 & -0.36 & -0.19 \\
Bulk density & 0.38 & 0.27 & 0.13 \\
Available water & $-0.65^{* * *}$ & -0.21 & -0.26 \\
Hydraulic conductivity & $-0.60^{* * *}$ & $-0.46^{*}$ & $-0.49^{* *}$ \\
Aggregate mean diameter & $-0.66^{* * *}$ & -0.06 & -0.09 \\
Water stable aggregate & $-0.64^{* * *}$ & -0.10 & -0.21 \\
\hline
\end{tabular}

$* p<0.05$.

$* * p<0.01$.

$* * * p<0.001$. 
available by the decline of microbial biomass seen in response to Tillage Events 3 and 4. Other soils submitted to disturbances have expressed contradictory results regarding substrate utilization in Biolog systems. For instance, metabolism of carbohydrates in Biolog EcoPlate declined in soils under conventional tillage compared with reduced tillage management (Diosma et al., 2006). Although this result partially corroborates ours, other cultivated soils did not differ in the metabolism of 30 different carbohydrates in Biolog GN microplates in comparison with uncultivated paired sites (Yan et al., 2000). Instead, the microbial community from the cultivated soils utilized fewer carboxylic acids, amino acids, and amines/amides. It is interesting to speculate that the response of CLPPs to disturbances 2 through 4 , without concomitant community shifts (as detected by T-RFLP patterns), reflects on the resistance and resilience of the soil community structure that developed in response to the first tillage event. Further work is needed to study the details of the community shift, and to attempt to directly link the CLPPs responses to specific changes in nutrient status and/or the physical environment during progression through tillage events.

Changes in PLFA profiles in response to disturbances were less clear despite a significant change in plots subjected to the highest disturbance level (Fig. 2C). Interestingly, even though microbial biomass per se, and several PLFA biomarkers of specific microbial types declined across the gradient, as might be expected, there was a linear decrease in the ratio of the cyclopropyl PLFA (19:0cy) to its precursor $(18: 1 \omega 7 \mathrm{c})(p<0.001)$ (Fig. 3). This ratio has been referred to as an indicator of the physiological status of Gram-negative bacterial communities (Law et al., 1963; Bossio and Scow, 1998; Bossio et al., 1998). In these bacteria, the precursors are increasingly converted to cyclopropyl fatty acids as bacteria transition from growth to no growth state. Therefore, a decrease of this ratio across the disturbance gradient might imply alleviation of a substrate limited condition and/or turnover of the dead or dormant biomass by some fraction of the microbial community. This is consistent with the physiological profile changes observed in the CLPPs across the gradient.

The disturbance gradient also negatively affected estimates of both the microbial genotypic diversity, and substrate utilization profiles as indicated by the negative correlation between richness $(R)$ and Shannon $\left(H^{\prime}\right)$ indexes with T-RFLP and CLPP profiles (Table 4). Decreases in the diversity of microbial substrate utilization profiles based on CLPP analyses have also been observed in several soils that have undergone changes in land use or intensive soil cultivation (Bossio et al., 2005; Degens et al., 2000; Diosma et al., 2006; Gomez et al., 2000, 2004; Lupwayi et al., 1998; Nsabimana et al., 2004; Yan et al., 2000). Nonetheless, fewer DNA-based studies have demonstrated similar changes in microbial diversity (Buckley and Schmidt, 2001; Torsvik et al., 2002). Studies where both CLPP and T-RFLP analyses were used to compare soils under different land use (native vegetation, perennial or annual crops) have revealed differences only in diversity indexes based on CLPPs (Bossio et al., 2005; Gomez et al., 2004).

With few exceptions (Diosma et al., 2006; Lupwayi et al., 1998), all studies cited above compared the microbial community from soils under different types of vegetation or diversity of plants. Considering that vegetation can have a major influence on soil microbial diversity and composition (Berg et al., 2002; Grayston et al., 2004; Hackl et al., 2004; Kowalchuk et al., 2002;
Smalla et al., 2001), it is difficult to separate changes caused by soil disturbance, from changes in vegetation composition. We believe that the influence of vegetation on microbial communities in our study were minimal because: (i) the whole study area was covered with relatively homogeneous vegetation for $12 \mathrm{yr}$ before the experimental setting; and (ii) minimal vegetation growth was permitted on the experimental plots for most of the study by chemical desiccation and periodic mowing. Therefore, effects of the disturbance gradient on microbial diversity and composition reported in this study are more likely to be directly associated with the disturbances applied to the soil.

Changes in CLPPs relative to control soils were significantly associated with the degradation of most soil physical and chemical properties analyzed (Table 5), whereas microbial community composition based on T-RFLP and PLFA profiles were significantly associated only with soil $\mathrm{C}$ and hydraulic conductivity. Other studies have found significant correlations between microbial community composition and soil $\mathrm{C}$ in areas under different land use (Cookson et al., 2007), soil management (Grayston et al., 2004; Yan et al., 2000), or along a chronosequence of soil restoration (Gros et al., 2004). As discussed previously, nonedaphic factors might have influenced the results of these studies. However, our results indicate that the losses of SOC and degradation of soil structure shown in those studies might indeed be associated with changes in microbial community composition and decreases in diversity indexes.

\section{CONCLUSIONS}

This study aimed to: 1 . generate a gradient of induced soil degradation through varying the number of tillage events; 2 . study changes in microbial community composition and diversity across the induced gradient; and 3. compare the ability of different methods to assess the response of microbial communities to soil degradation. We have shown that the induced gradient resulted in an altered and less diverse microbial community, and that these changes were directly associated with losses of SOC and degradation of soil physical structure. Results from CLPP, T-RFLP, and PLFA profiling techniques indicate that the level of soil disturbance/degradation uncouples the response of microbial community activities from compositional shifts. Further research is needed to understand the critical factors that influence when microbial physiological responses are coupled or uncoupled from community composition shifts and their impact on soil functions.

\section{ACKNOWLEDGMENTS}

We are grateful to the crew from Embrapa Tabuleiros Costeiros for their assistance in field operations, and to Fernando L. Cintra for assistance in soil physical analyses. Special thanks go to Rama Ghimire, Stephanie Yarwood, Elizabeth Brewer, and Nicole DeCrappeo for their assistance in T-RFLP and CLPP analyses. This study was funded in part by grant from the Empresa Brasileira de Pesquisa Agropecuária (Embrapa). The first author also acknowledges fellowship support from the Brazilian Federal Agency for Graduate Education (CAPES).

\section{REFERENCES}

Berg, G., N. Roskot, A. Steidle, L. Eberl, A. Zock, and K. Smalla. 2002. Plantdependent genotypic and phenotypic diversity of antagonistic rhizobacteria isolated from different Verticillium host plants. Appl. Environ. Microbiol. $68: 3328-3338$. 
Bossio, D.A., and K.M. Scow. 1998. Impacts of carbon and flooding on soil microbial communities: Phospholipid fatty acid profiles and substrate utilization patterns. Microb. Ecol. 35:265-278.

Bossio, D.A., K.M. Scow, N. Gunapala, and K.J. Graham. 1998. Determinants of soil microbial communities: Effects of agricultural management, season, and soil type on phospholipid fatty acid profiles. Microb. Ecol. 36:1-12.

Bossio, D.A., M.S. Girvan, L. Verchot, J. Bullimore, T. Borelli, A. Albrecht, K.M. Scow, A.S. Ball, J.N. Pretty, and A.M. Osborn. 2005. Soil microbial community response to land use change in an agricultural landscape of Western Kenya. Microb. Ecol. 49:50-62.

Brady, N.C., and R.R. Weil. 2002. The nature and properties of soils. 13rd ed. Prentice Hall, Upper Saddle River, NJ.

Buckley, D.H., and T.M. Schmidt. 2001. The structure of microbial communities in soil and the lasting impact of cultivation. Microb. Ecol. 42:11-21.

Butler, J.L., M.A. Williams, P.J. Bottomley, and D.D. Myrold. 2003. Microbial community dynamics associated with rhizosphere carbon flow. Appl. Environ. Microbiol. 69:6793-6800.

Cookson, W.R., M. Osman, P. Marschner, D.A. Abaye, I. Clark, D.V. Murphy, E.A. Stockdale, and C.A. Watson. 2007. Controls on soil nitrogen cycling and microbial community composition across land use and incubation temperature. Soil Biol. Biochem. 39:744-756.

Dane, J.H., and J.W. Hopmans. 2002. Water retention and storage. p. 688-690. In J.H. Dane and G.C. Topp (ed.) Methods of soil analysis. Part 4. SSSA, Madison, WI.

Degens, B.P., L.A. Schipper, G.P. Sparling, and M. Vojvodic-Vukovic. 2000. Decreases in organic $\mathrm{C}$ reserves in soils can reduce the catabolic diversity of soil microbial communities. Soil Biol. Biochem. 32:189-196.

Diosma, G., M. Aulicino, H. Chidichimo, and P.A. Balatti. 2006. Effect of tillage and $\mathrm{N}$ fertilization on microbial physiological profile of soils cultivated with wheat. Soil Tillage Res. 91:236-243.

Doran, J.W., E.T. Elliott, and K. Paustian. 1998. Soil microbial activity, nitrogen cycling, and long-term changes in organic carbon pools as related to fallow tillage management. Soil Tillage Res. 49:3-18.

Edwards, U., T. Rogall, E.M. Blöcker, and E.C. Böttger. 1989. Isolations and direct complete nucleotide determination of entire genes. Characterization of a gene coding $16 \mathrm{~S}$ ribosomal RNA. Nucleic Acids Res. 17:7843-7852.

Elliott, E.T. 1986. Aggregate structure and carbon, nitrogen, and phosphorus in native and cultivated soils. Soil Sci. Soc. Am. J. 50:627-633.

Embrapa. 1997. Manual de métodos de análise de solo. 2nd ed. Embrapa CNPS, Rio de Janeiro.

Frostegård, Å., and E. Bååth. 1996. The use of phospholipid fatty acid analysis to estimate bacterial and fungal biomass in soil. Biol. Fertil. Soils 22:59-65.

Garland, J.L., and A.L. Mills. 1991. Classification and characterization of heterotrophic microbial communities on the basis of patterns of communitylevel sole-carbon-utilization. Appl. Environ. Microbiol. 57:2351-2359.

Gomez, E., V. Bisaro, and M. Conti. 2000. Potential C-source utilization patterns of bacterial communities as influenced by clearing and land use in a vertic soil of Argentina. Appl. Soil Ecol. 15:273-281.

Gomez, E.D., J.L. Garland, and M.S. Roberts. 2004. Microbial structural diversity estimated by dilution-extinction of phenotypic traits and T-RFLP analysis along a land-use intensification gradient. FEMS Microbiol. Ecol. 49:253-259.

Grayston, S.J., C.D. Campbell, R.D. Bardgett, J.L. Mawdsley, C.D. Clegg, K. Ritz, B.S. Griffiths, J.S. Rodwell, S.J. Edwards, W.J. Davies, D.J. Elston, and P. Millard. 2004. Assessing shifts in microbial community structure across a range of grasslands of differing management intensity using CLPP, PLFA and community DNA techniques. Appl. Soil Ecol. 25:63-84.

Gros, R., L.J. Monrozier, F. Bartoli, J.L. Chotte, and P. Faivre. 2004. Relationships between soil physico-chemical properties and microbial activity along a restoration chronosequence of alpine grasslands following ski run construction. Appl. Soil Ecol. 27:7-22.

Grossman, R.B., and T.G. Reinsch. 2002. Bulk density and linear extensibility. p. 201-225. In J.H. Dane and G.C. Topp (ed.) Methods of soil analysis. Part 4. SSSA, Madison, WI.

Hackl, E., S. Zechmeister-Boltenstern, L. Bodrossy, and A. Sessitsch. 2004. Comparison of diversities and compositions of bacterial populations inhabiting natural forest soils. Appl. Environ. Microbiol. 70:5057-5065.

Jackson, L.E., F.J. Calderon, K.L. Steenwerth, K.M. Scow, and D.E. Rolston. 2003. Responses of soil microbial processes and community structure to tillage events and implications for soil quality. Geoderma 114:305-317.
Kemper W.D., Roseneau, R.C. 1986. Aggregate stability and size distribution. p.425-441. In A. Klute (ed). Methods of soil analysis. Part 1. ASA and SSSA, Madison, WI.

Kohler, F., J. Hamelin, F. Gillet, J.M. Gobat, and A. Buttler. 2005. Soil microbial community changes in wooded mountain pastures due to simulated effects of cattle grazing. Plant Soil 278:327-340.

Kowalchuk, G.A., D.S. Buma, W. de Boer, P.G.L. Klinkhamer, and J.A. van Veen. 2002. Effects of above-ground plant species composition and diversity on the diversity of soil-borne microorganisms. Antonie van Leeuwenhoek 81:509-520.

Kruskal, J.B. 1964a. Multidimensional scaling by optimizing goodness of fit to a nonmetric hypothesis. Psychometrika 29:1-27.

Kruskal, J.B. 1964b. Nonmetric multidimensional scaling: A numerical method. Psychometrika 29:115-129.

Law, J.H., H. Zalkin, and T. Kaneshiro. 1963. Transmethylations reactions in bacterial lipids. Biochim. Biophys. Acta 70:143-151.

Lupwayi, N.Z., G.W. Clayton, and W.A. Rice. 1998. Soil microbial diversity and community structure under wheat as influenced by tillage and crop rotation. Soil Biol. Biochem. 30:1733-1741.

Muyzer, G., G. Teske, C.O. Wirsen, and H.W. Jannasch. 1995. Phylogenetic relationships of Thiomicrospira species and their identification in deep-sea hydrothermal vent samples by denaturing gradient gel electrophoresis of 16S rDNA fragments. Arch. Microbiol. 164:165-172.

Nelson, D.W., and L.E. Sommers. 1996. Total carbon, organic carbon, and organic matter. p. 961-1010. In D.L. Sparks (ed.) Methods of soil analysis. Part 3. 2nd ed. SSSA, Madison, WI.

Nimmo, J.R., and K.S. Perkins. 2002. Aggregate stability and size distribution. p. 317-328. In J.H. Dane and G.C. Topp (ed.) Methods of soil analysis. Part 4. SSSA, Madison, WI.

Nsabimana, D., R.J. Haynes, and F.M. Wallis. 2004. Size, activity and catabolic diversity of the soil microbial biomass as affected by land use. Appl. Soil Ecol. 26:81-92.

Olsson, P.A., E. Bååth, I. Jakobsen, and B. Söderström. 1995. The use of phospholipid and neutral lipid fatty acids to estimate biomass of arbuscular mycorrhizal fungi in soil. Mycol. Res. 99:623-629.

Reynolds, W.D., D.E. Elrick, and E.G. Youngs. 2002. Single-ring and double- or concentric-ring infiltrometers. p. 821-826. In J.H. Dane and G.C. Topp (ed.) Methods of soil analysis. Part 4. SSSA, Madison, WI.

Rich, J.J., R.S. Heichen, P.J. Bottomley, K. Cromack, Jr., and D.D. Myrold. 2003. Community composition and functioning of denitrifying bacteria from adjacent meadow and forest soils. Appl. Environ. Microbiol. 69:5974-5982.

Schimel, J., T.C. Balser, and M. Wallenstein. 2007. Microbial stress-response physiology and its implications for ecosystem function. Ecology 88:1386-1394.

Sinsabaugh, R.L., M.J. Klug, H.P. Collins, P.E. Yeager, and S.O. Peterson. 1999. Characterizing soil microbial communities. p. 318-347. In G. P. Robertson et al. (ed.) Standard soil methods for long-term ecological research. Oxford Univ. Press, New York.

Smalla, K., G. Wieland, A. Buchner, A.Zock, J.Parzy, S. Kaiser, N. Roskot, H. Heuer and G. Berg. 2001. Bulk and rhizosphere soil bacterial communities studied by denaturing gradient gel electrophoresis: Plant-dependent enrichment and seasonal shifts revealed. Appl. Environ. Microbiol. 67:4742-4751.

Torsvik, V., L. Øvreås, and T.F. Thingstad. 2002. Prokaryotic diversityMagnitude, dynamics, and controlling factors. Science 296:1064-1066.

White, D.C., H.C. Pinkart, and D.B. Ringelberg. 1997. Biomass measurements: Biochemical approaches. p. 91-101. In C.J. Hurst and G.R. Knudsen (ed.) Manual of environmental microbiology. ASM Press, Washington, DC.

Woods, L. 1989. Active organic matter distribution in the surface $15 \mathrm{~cm}$ of undisturbed and cultivated soil. Biol. Fertil. Soils 8:272-278.

Yan, F., A.B. McBratney, and L. Copeland. 2000. Functional substrate biodiversity of cultivated and uncultivated A horizons of vertisols in NW New South Wales. Geoderma 96:321-343.

Zelles, L. 1999. Fatty acid patterns of phospholipids and lipopolysaccharides in the characterization of microbial communities in soil: A review. Biol. Fertil. Soils 29:111-129.

Zelles, L., Q.Y. Bai, T. Beck, and F. Beese. 1992. Signature fatty acids in phospholipids and lipopolysaccharides as indicators of microbial biomass and community structure in agricultural soils. Soil Biol. Biochem. 24:317-323.

Zibilske, L.M. 1994. Carbon Mineralization. p. 835-863. In R.W. Weaver et al (ed.) Methods of soil analysis. Part 2. SSSA, Madison, WI. 